Article

\title{
Semi-Transparent Energy-Harvesting Solar Concentrator Windows Employing Infrared Transmission-Enhanced Glass and Large-Area Microstructured Diffractive Elements
}

\author{
Mikhail Vasiliev ${ }^{1, *(\mathbb{D})}$, Kamal Alameh ${ }^{1}$, Mohsin Ali Badshah ${ }^{2}$, Seok-Min Kim ${ }^{2}$ and \\ Mohammad Nur-E-Alam ${ }^{1}$ (D) \\ 1 Electron Science Research Institute (ESRI), Edith Cowan University, 270 Joondalup Dr, 6027, WA, Australia; \\ k.alameh@ecu.edu.au (K.A.); m.nur-e-alam@ecu.edu.au (M.N.-E.-A.) \\ 2 School of Mechanical Engineering, Chung-Ang University, Seoul 06974, Korea; \\ mohsinali@cau.ac.kr (M.A.B.); smkim@cau.ac.kr (S.M.K.) \\ * Correspondence: m.vasiliev@ecu.edu.au
}

Received: 23 July 2018; Accepted: 15 August 2018; Published: 17 August 2018

\begin{abstract}
We report on the study of energy-harvesting performance in medium-size $\left(400 \mathrm{~cm}^{2}\right)$ glass-based semitransparent solar concentrators employing edge-mounted photovoltaic modules. Systems using several different types of glazing system architecture and containing embedded diffractive structures are prepared and characterized. The technological approaches to the rapid manufacture of large-area diffractive elements suitable for use in solar window-type concentrators are described. These elements enable the internal deflection and partial trapping of light inside glass-based concentrator windows. We focus on uncovering the potential of pattern-transfer polymer-based soft lithography for enabling both the improved photon collection probability at solar cell surfaces, and the up-scaling of semitransparent solar window dimensions. Results of photovoltaic characterization of several solar concentrators employing different internal glazing-system structure and diffractive elements produced using different technologies are reported and discussed.
\end{abstract}

Keywords: solar windows; advanced glazings; diffractive elements; light trapping; photovoltaics

\section{Introduction}

The development of luminescent solar concentrators (LSC) and other types of semitransparent solar photovoltaic (PV) systems is at present rapidly transforming into a mature research field, with its origins dating back to the 1970s [1,2]. A large number of works have since been dedicated to achieving continued progress in enabling solar energy collection in planar window-type concentrators employing various luminescent materials, solar cell types, and device structures [3,4]. More recently, multiple research groups worldwide have concentrated their efforts towards demonstrating large-area luminescent concentrators and the development of advanced luminescent materials for use in window-type concentrators suitable for deployment in built environments [5-9]. A notable trend in the recently-reported works is the growing shift away from using organic photoluminescent dyes (which have been used traditionally in LSC devices for several decades) towards the more chemicallyand photo-stable inorganic phosphors and quantum dots [6-8,10-12], which can significantly reduce re-absorption losses within luminescent media. These functional materials can be incorporated into planar concentrator structures by way of forming the phosphor particle-loaded planar luminescent interlayers [10], or phosphor films [12]. Whilst the functional materials remain at the cutting edge of luminescent concentrator research $[13,14]$, other system design features such as spectrally-selective 
coatings, specialty glass types, solar-cell module type and configuration, and the glazing system architecture are receiving increased attention. Of notable importance is the recent development of a new float glass type possessing significantly reduced optical absorption in the near-infrared wavelength range (TIREX by AGC Europe, [15]). We tested experimentally several concentrator devices built using this glass type and characterised the energy harvesting performance improvements in terms of standard metrics parameters applicable to LSC-type devices.

At present, transparent solar windows and multiple other types of semi-transparent building-integrated PV (BIPV), or building-applied PV (BAPV) energy-generating modules based on different technologies are starting to be mass-produced and deployed commercially worldwide [16-19]. The growing industry of net-zero energy buildings (NZEB, [19-21]) construction benefits from the synergy of the on-site distributed energy generation provided by BIPV (or solar window) products, and the energy-saving functionality provided by the structure of advanced glazings containing transparent heat-regulating (low-emissivity) coatings [22-24]. The development of energy-generating window products occurs in synergy with another area of active research dedicated to optimizing the ways in which the electric output can be extracted, stored, and utilized in distributed low- and medium-power installations [25-27]. Often, advanced solar window designs themselves combine the energy generation capabilities with significant potential for reducing the lighting, heating, and cooling expenditures in buildings [17,28]. Excellent recent reviews and other articles (including [4,7,8,12-14]) dedicated to the current state of the field in semi-transparent luminescent concentrators of all types and solar window development present multiple datasets related to the system performance characteristics demonstrated to date.

Embedding large-area finely-structured elements (such as diffractive optical elements [28-30], or light diffuser films [31]) into the glazing system of solar PV windows is a proven and fruitful approach to maximizing their energy harvesting performance. In order to maximize the number of potential industrial applications of these solar windows, of particular importance are the technologies suitable for mass-fabrication of custom-designed large-area diffractive deflectors (or diffusers), and the balance between their energy-harvesting performance and visible-range transparency. Since our original report on embedding multiple small-area transparent diffraction gratings produced by lift-off photolithography into various solar windows [28], several alternative (and more cost-effective) technical approaches to the manufacture of microstructured diffractive elements have been trialed. We recently explored the energy-harvesting potential of transparent gratings produced by pattern replication processes based on soft lithography techniques [32-35]. In this paper, we report on the process details and the principal results achieved with diffraction-assisted glass-based solar concentrator windows, $200 \mathrm{~mm} \times 200 \mathrm{~mm}$ in size, in the subsequent sections. The energy-collection performance of diffractive elements fabricated using different technological approaches is also discussed and compared with the energy harvesting results achieved in flat-glass solar concentrators using either the low-iron or specialty glass.

\section{Energy Harvesting Potential of Diffractive Elements and Low-Absorption Specialty Glass Panels Embedded into the Structure of Solar Windows}

Apart from the light trapping by the total internal reflection mechanism reliant on luminescence emissions, other possibilities exist for the coupling of a part of the incident solar energy flux into the "guided modes" which can propagate inside (and in-between) the glass panels of solar window glazings. One of the more standard ways of deflecting light rays into a number of angular directions involves the use of diffractive elements, which has been shown to improve the light collection efficiency in LSC-type concentrators, even in the case of highly transparent grating deflectors [28-30]. During this study, we tested the suitability of semi-transparent, small-period diffraction gratings produced by soft-lithography replication process, for use in solar windows. The main differences with our previous study [28] were related to testing, within this present work, of the suitability of small-periodicity ( $4 \mu \mathrm{m}$ pitch) and relatively shallow-depth (near $0.5 \mu \mathrm{m}$ ) patterned-polymer gratings, which could be 
mass-replicated from master gratings initially fabricated on quartz (or glass) substrates by conventional photolithography and plasma-etching processes. Another advantage of small-periodicity diffraction gratings is related to their relatively large angular deflection (compared to ray deflection angles achievable in long-period gratings having feature sizes measured in tens of $\mu \mathrm{m}$ ), even for the first-order diffracted beams. Small periodicity in grating deflectors implies invariably some visual distortions in the transmitted images ("rainbow effect"), which is why these deflector elements may be useful if installed only at around the near-perimeter areas of solar window glass panels. We also tested the potential of a specialty glass chemistry type (TIREX by AGC Europe) for improving the light collection efficiency in highly-transparent spectrally-selective concentrator windows, which favor multiple internal reflections of infrared (IR) light rays and require glass with very low absorption of light, particularly at wavelengths between 800-1300 nm.

\subsection{Experiments Highlighting the Contribution of Diffractive Elements to Light Diffusion Inside Glass and Near-Edge Flux Concentration}

The potential usefulness of diffraction gratings for enabling the enhanced diffusion and spreading of light inside planar concentrator structures and for increasing the light intensity at sample edges can be demonstrated using a simple lab experiment with a solar simulator (Figure 1).
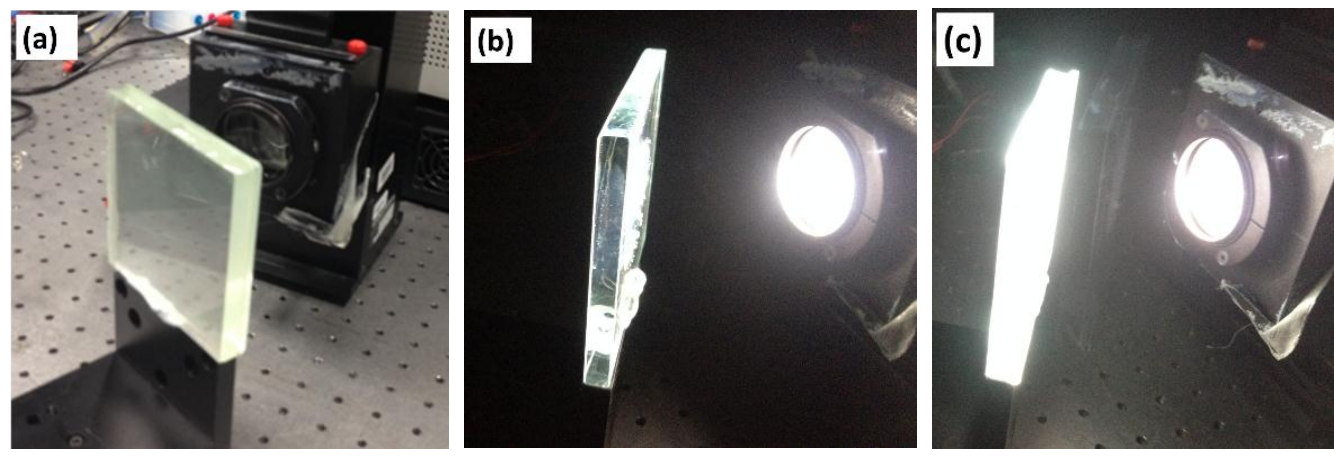

Figure 1. Visualization of enhanced internal diffusion of light inside microstructured glass panels. (a) Experimental set-up; (b) A $10 \mathrm{~mm}$-thick low-iron glass plate of size $100 \mathrm{~mm}$ x $100 \mathrm{~mm}$ with its central region exposed to a collimated light beam from a solar simulator; (c) an identical low-iron glass plate attached to a transparent 1D diffraction grating formed on a glass substrate of thickness $1 \mathrm{~mm}$. Both the grating and the interlayer were produced using the techniques described in detail in [28].

The structured glass sample (Figure 1c) contained a visible-range transparent 1D diffraction grating of period $20 \mu \mathrm{m}$, which generated almost no transmitted-image distortions or significant "rainbow effect" coloration. The grating structure was fabricated on a thin glass substrate by a photolithography-assisted lift-off process applied to a custom-designed optical thin-film coating. This patterned coating was designed to optimize the diffraction efficiency of the normally-incident UV-blue and also the near-IR light rays into its \pm 1 st transmitted orders and also into higher odd-valued transmitted orders. The grating grooves were filled by a UV-curable clear optical epoxy interlayer containing inorganic luminescent particles (with their concentration being less than $0.1 \mathrm{wt} \%$ ) prior to attaching the grating plate to a $10 \mathrm{~mm}$-thick low-iron glass plate identical to that shown in Figure $1 \mathrm{~b}$. The interlayer thickness was $(0.5 \pm 0.1) \mathrm{mm}$, and the grating height was less than $1 \mu \mathrm{m}$. Despite the significant visible-range transparency of the epoxy-filled grating plate (near $80 \%$ diffraction efficiency for zero-order visible transmission) being ensured by its design features (described in [28]), rather spectacular difference in the visual appearance (especially the edge-surface brightness) was revealed on illumination of both plates by a collimated 2" $(5.08 \mathrm{~cm})$ diameter beam from a solar simulator producing AM1.5G irradiation spectrum at $1000 \mathrm{~W} / \mathrm{m}^{2}$. The multiple scattering of the incident light by the luminophore particles located within or near the grating's grooves, in conjunction 
with diffraction by the grating, has led to the formation of a bright halo of diffused light intensity inside the structured-glass sample. This led consequently to a partial trapping of the incident optical flux inside glass plate, and thus to the increased edge-area brightness. The irradiation flux intensities coming out of the edge areas of these two samples measured by DayStar, Inc. (Las Cruces, NM, USA) handheld solar irradiation intensity meter differed by almost one order of magnitude for near-normal beam incidence angles.

\subsection{Energy Harvesting Performance of Flat-Glass Concentrators with and without Specialty Glass}

Solar windows of the hybrid concentrator type (as distinct from semi-transparent solar cell panels) employ a range of internal light redistribution mechanisms such as luminescence, total internal reflections, optical coating-assisted reflections, scattering, and diffraction. These mechanisms are intended to redirect a part of the solar energy flux incident onto the glazing system towards solar cells, which are typically placed at or near the glass panel edges. Multiple reflections are usually needed to occur in sequence at either the various glass-air interfaces, or at the optical coatings, in order to propagate the incident photon flux towards solar cell surfaces. In this situation, regardless of the location or angle of incidence, the probability of photon collection by the solar cells depends strongly on the absorption of either the incident, or re-emitted photons within both the glass panel material and within any coatings. It has been known that the optical absorption of even the ultraclear types of most commercially available low-iron glass is not negligible at near-IR wavelengths near $1000 \mathrm{~nm}$ [15]. This absorption reduces the direct transmission of glass plates (for normal incidence) by several percent already over the plate thicknesses near $10 \mathrm{~mm}$. When occurring over the decimetre-scale internal path-lengths within the glass, these effects of near-IR absorption are therefore expected to lead to losing tens of percent of the optical power in the near-IR flux which would otherwise be reaching the edge-mounted solar cells. We tested the performance of glass-based concentrators of size $200 \mathrm{~mm} \times 200 \mathrm{~mm}$, in which either the conventional low-iron glass, or the specialized (TIREX) glass with low IR-range absorption was used in conjunction with a single luminophore-loaded interlayer and an IR-specific transparent heat-mirror coating. The TIREX glass had a five times lower optical absorption coefficient in the near-infrared range, compared to the best of the extra-clear low-iron float glass types, due to its special chemical composition [15].

Two concentrator-type solar windows of identical glass areas have been constructed and tested to reveal the performance differences dependent on the glass type. The samples and their typical PV performance characteristics measured in outdoor conditions are shown in Figure 2. One of the window samples (Figure 2a) used two low-iron glass plates of total thickness $16 \mathrm{~mm}$ (a 10-mm plate connected through an epoxy interlayer to a $6 \mathrm{~mm}$ plate coated by VNE 2463 low-emissivity spectrally-selective coating by Viracon Inc., Owatonna, MN, USA) and ( $26 \pm 0.5) \mathrm{mm} \times 198 \mathrm{~mm}$ PV module cut-outs from the active circuit of Avancis PowerMax $3.5130 \mathrm{CuInSe}_{2}$ panel product (Avancis Inc, Torgau, Germany). This solar window was placed into a standard commercial plastic framing system, which has not affected its energy-harvesting performance measurably. The second solar window sample used three 4mm-thick TIREX glass plates of size $200 \mathrm{~mm} \times 200 \mathrm{~mm}$, two of which were connected by a luminophore-loaded epoxy interlayer identical to that of the first window, and the other $0.5 \mathrm{~mm}$-thick interlayer contained only clear UV-cured epoxy. One of TIREX glass plates was coated by a low-emissivity spectrally-selective coating of our design [10], the transmission and reflection spectra of which were almost identical to the coating used in the framed sample. The PV modules installed at the edges were cut-outs from the active circuit of Avancis PowerMax $3.5140 \mathrm{CuInSe}_{2}$ panel product, of dimensions $(17 \pm 0.5) \mathrm{mm} \times 198 \mathrm{~mm}$, and had a marginally higher nominal module efficiency compared to the PV modules used in the framed sample (13.3\% vs $12.2 \%$ ).

Both solar windows were tested several times in similar outdoor conditions when placed into the vertical sun-facing position, at solar irradiation flux conditions not exceeding $1000 \mathrm{~W} / \mathrm{m}^{2}$, and measured at the stabilized solar cell surface temperatures of above $40{ }^{\circ} \mathrm{C}$. The summary of characterization results and the measured data are also presented in Figure 2. 


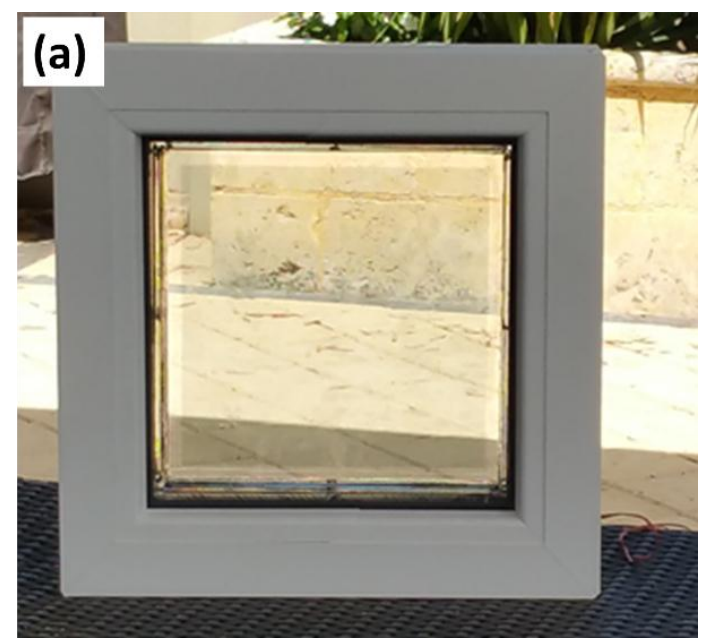

0.06
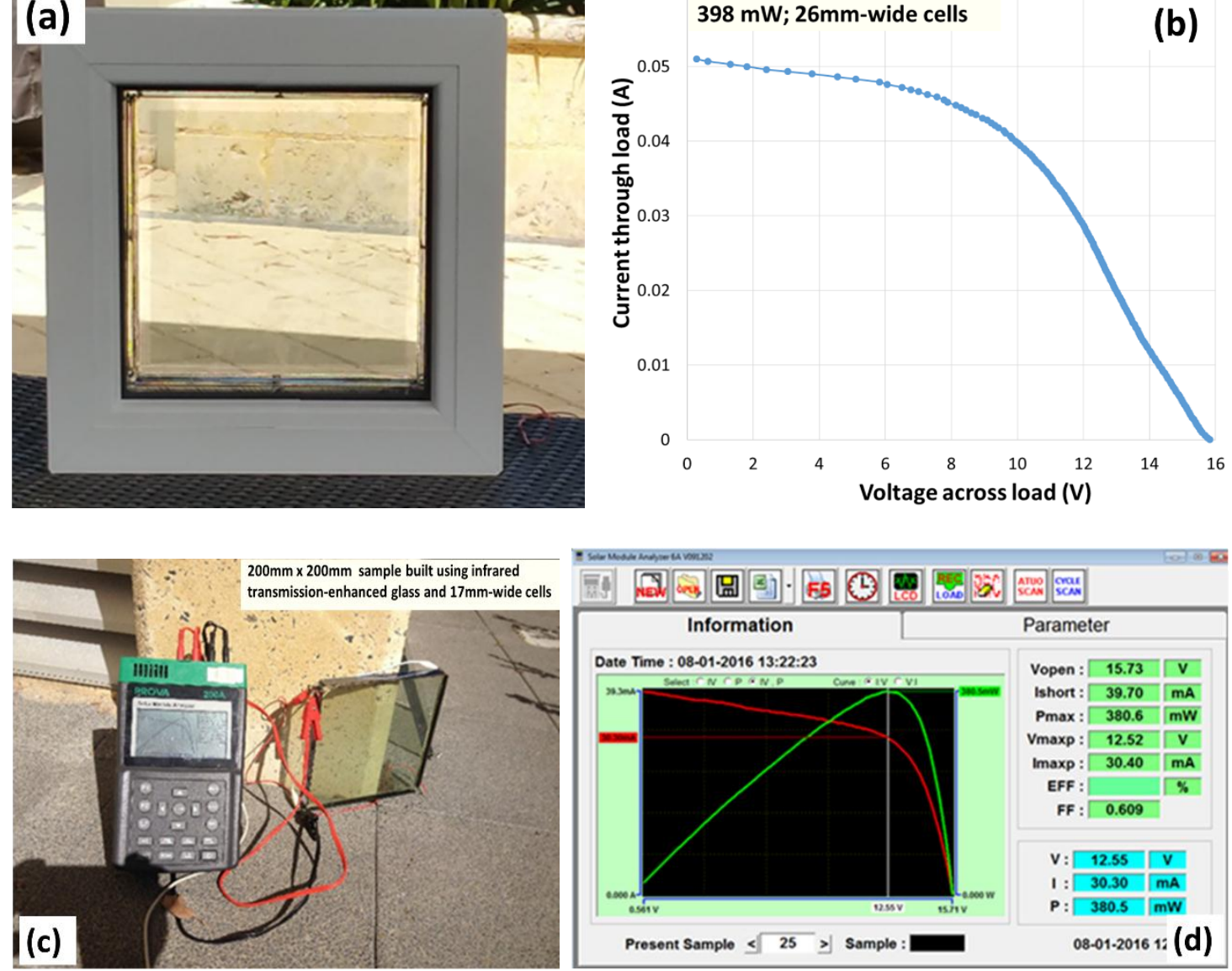

Figure 2. Samples of $200 \mathrm{~mm} \times 200 \mathrm{~mm}$ solar window-type concentrator prototypes. (a,b) A flat-glass (unstructured) concentrator employing $26 \mathrm{~mm}$-wide cells at glass panel edges and its measured I-V curve; (c,d) A flat-glass $200 \mathrm{~mm} \times 200 \mathrm{~mm}$ concentrator employing $17 \mathrm{~mm}$-wide cell modules and a specialty glass type (TIREX, AGC Europe) of enhanced transmission in the near-IR range; its measured $\mathrm{I}-\mathrm{V}$ curve is also shown.

Interestingly, despite a significant difference in the width of the active PV modules installed into these solar-window samples (the total active areas of cells varying by over $50 \%$ ), only a marginal difference (of less than $5 \%$ ) was seen in their electric power output. It is also of notable importance that the sample built from low-absorption glass demonstrated a combined module fill factor (FF) of 0.609 , which was significantly higher than that measured in the framed sample (0.489). Both windows used parallel electric connections between all four PV modules followed by a series-connected blocking diode each. The higher module FF suggests obtaining smaller electric mismatch loss caused by the open-circuit voltage $\left(\mathrm{V}_{\text {oc }}\right)$ differences between the different $\mathrm{PV}$ modules receiving different amounts of light. These results highlight the role of low-absorption glass in the energy collection process, and have later been re-confirmed in larger-area solar window samples using TIREX glass instead of conventional low-iron glass. Another notable feature of concentrator windows built using low-absorption glass is the broader angular orientation range in which the windows generate their near-peak power, which will be reported in more quantitative detail elsewhere. The visible-range transmission of TIREX glass plates is slightly below that measured in most low-iron extra-clear glass types of identical thickness, however, due to the spectral selectivity of the coatings and luminophores targeting the preferential capture of near-IR light, this does not hinder the energy collection performance. 


\section{Materials and Technologies Used for the Cost-Effective Manufacture of Large-Area Semitransparent Diffractive Elements and Solar Concentrator Panels}

The transparent (or semitransparent) diffractive elements contribute to the efficiency of concentrator-type solar windows by way of providing an increased probability of photon trapping and ray re-direction without adding absorption and quantum yield-related losses. The principal design features of diffraction gratings that define their potential usefulness for randomising the light-ray propagation directions (and thus keeping a fraction of propagating light energy inside the glazing system and outside the "escape cone" directions) are their periodicity and depth. In the case of gratings grown on (or applied to), any glass-substrate surfaces, for example, the gratings formed by laser-patterned optical coatings, or fabricated as lift-off lithography-patterned coatings, the optical properties of the grating material itself are of high importance and also define the functionality of the solar concentrator. Glass panel surfaces can themselves be subjected to microlithography patterning and plasma etching processes to form diffractive elements using the glass-air interfaces, or (generally in the case of patterned-coating grating formation process) the grooves of diffraction gratings can be filled with any suitable transparent optical epoxy with or without added phosphor particles or luminescent dyes. The main objective of the semi-transparent diffractive element design (for use of these components in LSC-type devices) is to achieve the maximum possible angular deflection of the incident rays to be harvested, for a large range of possible incidence angles, which necessitates minimization of the grating period and (if high transparency within any particular spectral range is required) achieving a good degree of control over the grating depth and pattern quality. Experimental techniques such as photolithography (followed by either etching or lift-off processes) are adequate for the development of proof-of-concept structures, yet are not cost-efficient for the mass production of large-area grating structures. Patterning optical coatings using laser engraver-type systems is a practical way of forming large-area diffractive elements, however the minimum feature size (and periodicity) are limited (to about $20 \mu \mathrm{m}$ ) by factors such as the focus spot size, graphics image-pattern rendering, and mechanical translation-stage resolution.

Soft lithography approaches can provide significant cost reductions for the manufacturers of large solar window devices using diffractive elements of small feature size. This is because replicated "master grating" produced by soft lithography process can be used as a single template for multiple replications with high reproducibility [32-34]. The photolithography and etching techniques can provide excellent reproducibility of patterns, however, the fabrication processes have not been commercially viable in the past, especially for large-scale applications. In this study, large-area diffraction grating patterns on glass substrates were fabricated by employing a double replication process, as shown in Figure 3. A quartz master grating of periodicity $4 \mu \mathrm{m}$, groove depth near $0.5 \mu \mathrm{m}$, and $50 \%$ duty cycle fabricated by photolithography and reactive-ion etching process, was dipped in the $2 \%$ dimethyldichlorosilane dissolved in octamethylcyclooctasilane (Repel-Silane ES, GE Healthcare Co., Ltd., Chicago, IL, USA) to apply a self-assembled monolayer as an anti-adhesion layer [35-37]. First, a replicated polydimethylsiloxane (PDMS) master template with master grating's structures were obtained from the quartz master by utilizing the soft lithography process [35,36], using a Sylgard 184 base and curing agent mixture (Dow Corning, Midland, Michigan) with 10:1 weight ratio, poured onto the master grating and cured at room temperature. In the second replication step, a UV-replication process similar to the soft-lithography step was conducted on the $130 \mathrm{~mm} \times 70 \mathrm{~mm} \times 3 \mathrm{~mm}$ low-iron glass substrates using the PDMS master template, and a UV-replicated grating pattern was formed within the cured optical epoxy layer on the glass substrate (Figure 3c,d). This was done by placing an uncured UV-curable acrylic epoxy layer (WTS-80203, Wan Ta Shing Ltd., Hong Kong, China) between the glass substrate and PDMS master template.

Figure 3 shows the details of the complete process sequence we have developed [35] for the mass-replication of large-area diffraction gratings inside soft polymer layers on glass substrates. 
Anti-adhesion

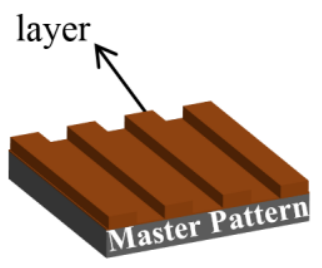

(a) RIE Master Grating Pattern

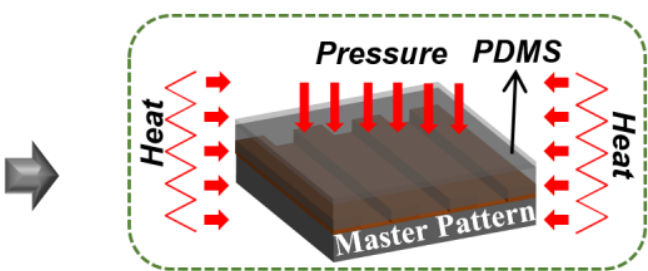

(b) $1^{\text {st }}$ Replication PDMS Replication

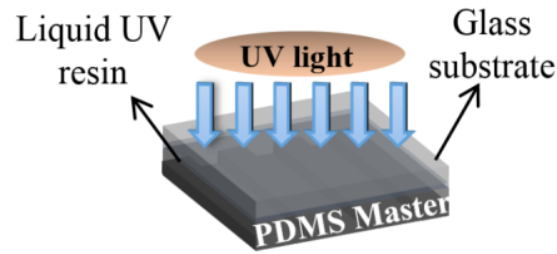

(c) $2^{\text {nd }}$ Replication UV Imprinting

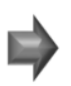

(d) Fabricated Grating Structure UV-Glass Grating

Figure 3. Soft lithography-based large-area diffraction grating replication process sequence.

A set of four $130 \mathrm{~mm} \times 70 \mathrm{~mm}$ diffraction gratings formed by a replicated pattern generated inside a layer of UV-curable acrylic epoxy on $3 \mathrm{~mm}$-thick low-iron glass substrates were used to embed around the perimeter of solar concentrator panel. The fabricated grating patterns faced the air inside an embedded air-gap positioned just behind the front-facing glass panel (200 $\mathrm{mm} \times 200 \mathrm{~mm}$, TIREX).

Figure 4 shows the diffractive elements fabricated, their visual appearance with some light concentration effects observed visually at the glass edge regions, the placement of gratings around the perimeter of front-side glass panel, and the characterisation details (line width/height measurements) of the master-grating. The linear features (grooves) of gratings were arranged to run along the long sides of all substrates. The master grating of periodicity $4 \mu \mathrm{m}$, groove depth near $0.5 \mu \mathrm{m}$, and $50 \%$ duty cycle has been fabricated be a plasma-etching process on a $200 \mathrm{~mm} \times 200 \mathrm{~mm} \times 1 \mathrm{~mm}$ quartz substrate by P-Cube Ltd (Seoul, Korea). The master-grating characterization dataset obtained by optical profilometry measurements has been supplied by the manufacturer.
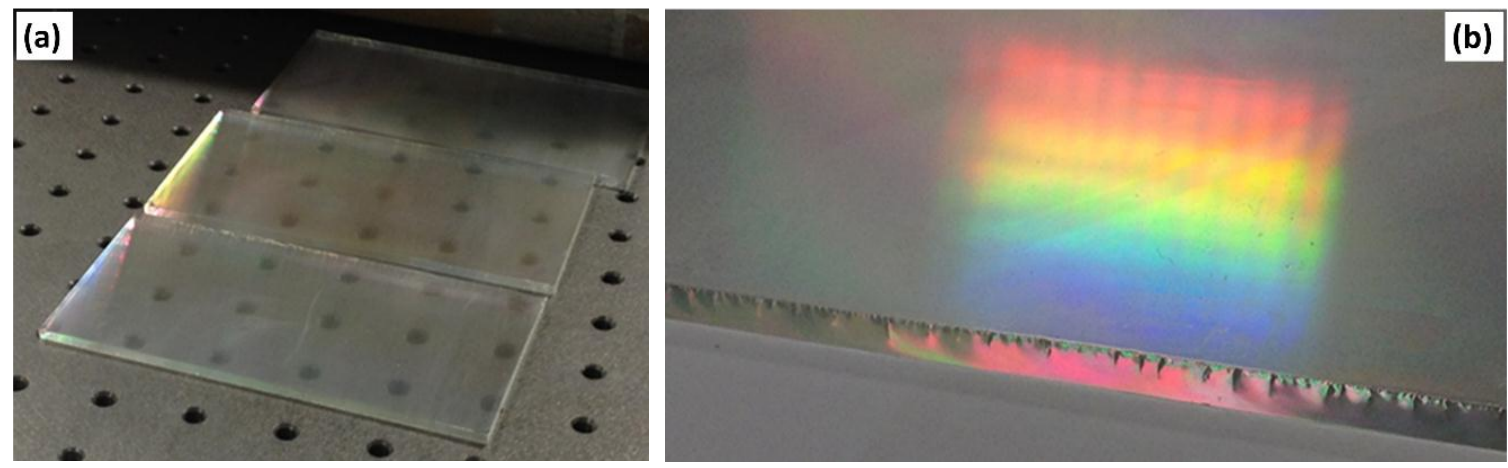

Figure 4. Cont. 


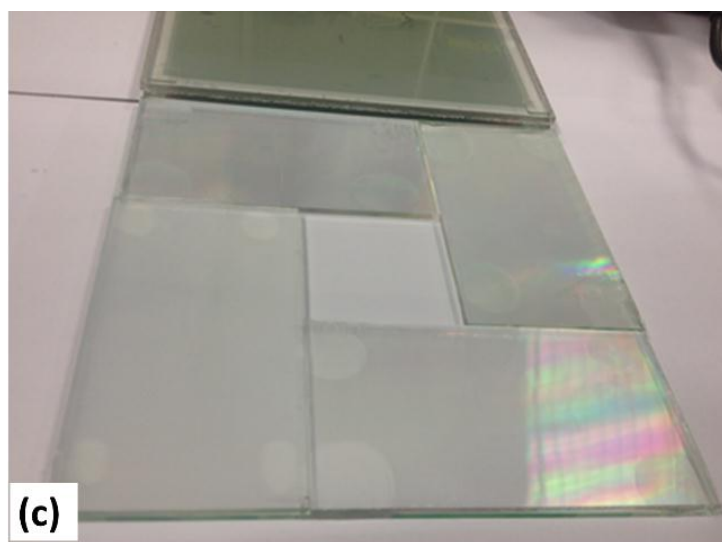

Process Result

1. Etch Depth

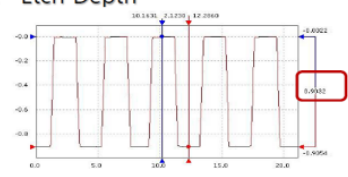

Grating Etch Depth [um]

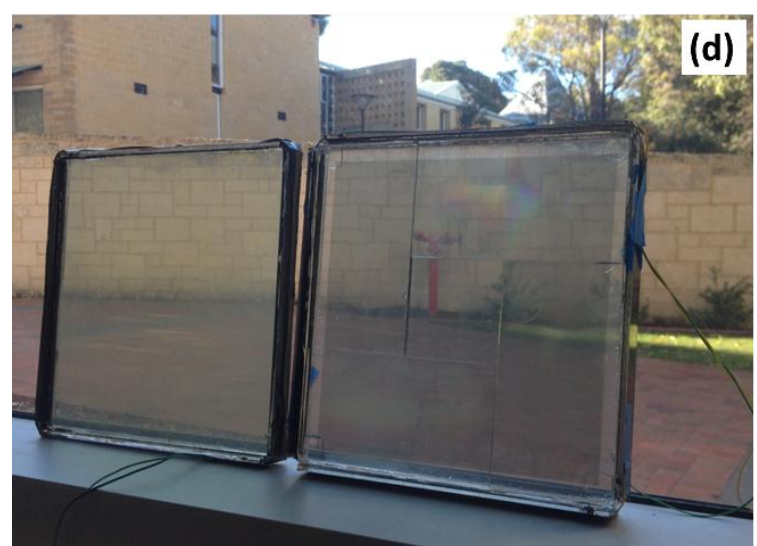

2. Grating Line Width

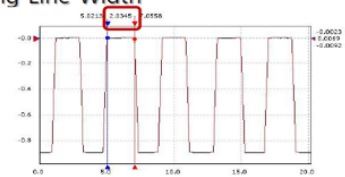

\begin{tabular}{|c|c|c|c|c|c|c|c|c|c|c|}
\hline \multirow{2}{*}{$5 / \mathrm{N}$} & \multicolumn{10}{|c|}{ Position } \\
\cline { 2 - 11 } & 1 & 2 & 3 & 4 & 5 & 6 & 7 & 8 & 9 & AVG \\
\hline $\mathrm{F}$ & 0.3936 & 0.407 & 0.3946 & 0.4145 & 0.4217 & 0.4114 & 0.4017 & 0.4113 & 0.398 & 0.41 \\
\hline 2 & 0.5039 & 0.5161 & 0.47 & 0.5098 & 0.514 & 0.4901 & 0.4999 & 0.4987 & 0.4939 & 0.50 \\
\hline
\end{tabular}

Grating Line Width [um]

\begin{tabular}{|c|c|c|c|c|c|c|c|c|c|c|}
\hline \multirow{2}{*}{$S / \mathrm{N}$} & \multicolumn{10}{|c|}{ Position } \\
\cline { 2 - 11 } & 1 & 2 & 3 & 4 & 5 & 6 & 7 & 8 & 9 & AVG \\
\hline $\mathrm{F}$ & 1.769 & 1.7682 & 1.789 & 1.7574 & 1.7432 & 1.7625 & 1.7465 & 1.74 & 1.7432 & 1.76 \\
\hline 2 & 1.9425 & 1.9487 & 1.9514 & 2.081 & 2.012 & 1.9537 & 2.0815 & 1.9763 & 2.0424 & 2.00 \\
\hline
\end{tabular}

P-CUBE

(e)

Figure 4. Components and structures used for constructing the $200 \mathrm{~mm} \times 200 \mathrm{~mm}$ glass-based diffraction grating-assisted solar concentrator panel. (a,b) $130 \mathrm{~mm} \times 70 \mathrm{~mm}$ low-iron glass substrates with acrylic epoxy replicated grating patterns, and the visual appearance of their edge regions; (c) Main components used to construct solar window concentrator panel: a low-emissivity coating (back) and a $3 \mathrm{~mm}$ TIREX front glass panel with four grating patterns attached using optical epoxy (front); (d) visual appearance of a flat glass-based sample (left) and the sample containing soft-lithography gratings (right); (e) Master grating profilometry characterization results.

The solar concentrator glass-panel sample was assembled using UV-curable optical epoxy, using small $1 \mathrm{~mm}$-thin glass adaptor plates of about $4 \mathrm{~mm} \times 4 \mathrm{~mm}$ size cut out from microscope slide glass, to form a $1 \mathrm{~mm}$-thick air-gap between the grating surfaces and the rest of glazing system. The latter was composed of a 6mm-thick low-iron glass plate coated by a Viracon VNE 2463 low-emissivity IR-reflector coating laminated using specialized $0.76 \mathrm{~mm}$-thick luminophore-loaded polyvinylbutyral (PVB) sheet to a 4mm-thick TIREX glass plate. The PVB interlayer material contained the luminescent material powders distributed inside the polymer, with the same luminophore particles chemistry and concentrations as used in the interlayer of framed $200 \mathrm{~mm} \times 200 \mathrm{~mm}$ sample of Figure 2a. Four strip-shaped CuInSe 2 solar-cell modules of dimensions $198 \mathrm{~mm} \times 18 \mathrm{~mm}$ were attached to glass panel edges using clear acrylic adhesive tapes of thickness $1 \mathrm{~mm}$. The solar-module strips were produced using a proprietary process which involved cutting, connectorization, and encapsulation of Avancis PowerMax3.5 140 active PV circuits. The encapsulation of PV strips was done using a thin layer of clear UV-curable epoxy and 1.1mm-thick low-iron cover-glass plates. All PV modules were connected in parallel electrically, with each being series-connected to a Schottky blocking diode. The technical reasons for selecting CuInSe ${ }_{2}$ over other PV module types (eg Si) for use in this application area have been discussed in some detail in [17]. 


\section{Custom-Shaped CuInSe 2 Modules and PV Performance of Individual Encapsulated Solar-Cell Strips}

The electric output performance of the strip-shaped encapsulated PV modules of sizes $198 \mathrm{~mm} \times 16 \mathrm{~mm}$ and also $198 \mathrm{~mm} \times 18 \mathrm{~mm}$ was characterized in outdoor illumination conditions on May 8th, 2018 at noon. The total (sum of the direct-beam and diffused) solar irradiation intensity was at less than $1000 \mathrm{~W} / \mathrm{m}^{2}$; the weather conditions corresponded to a typical warm $\left(\sim 22^{\circ} \mathrm{C}\right)$ sunny autumn day in Perth, Western Australia. According to the climate-related solar-irradiation datasets recorded for this location and taken from COMFEN 5 software [38] distributed by Lawrence Berkeley National Laboratory (LBNL, Berkeley, CA, USA), the mean highest monthly direct-beam irradiation intensity during May is near $869 \mathrm{~W} / \mathrm{m}^{2}$, which, accounting for the typical additional $10 \%$ from the diffused irradiation intensity, would result in the total maximum irradiation intensity figure of near $956 \mathrm{~W} / \mathrm{m}^{2}$. A portable PROVA 200 A solar module analyzer was used to record the I-V curve datasets of peak-oriented PV modules, after allowing the cell surface temperatures to stabilize at near $30^{\circ} \mathrm{C}$. The measured I-V characterization datasets and electric output parameters of these PV strips are shown in Figure 5.

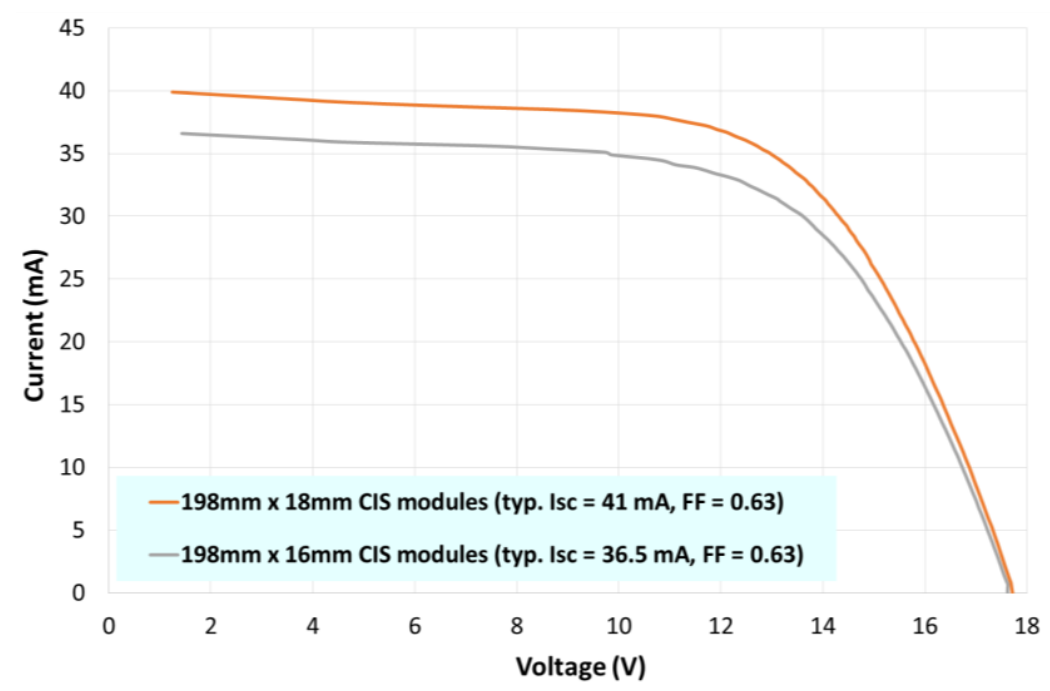

Figure 5. Measurements of the I-V curve data obtained with custom-shaped encapsulated CuInSe 2 PV strips (Avancis PowerMax 3.5140 ) in outdoor sunlight illumination conditions at noon. The strips were oriented to intercept maximum irradiation flux.

The differences in the widths of two different module types $(16 \mathrm{~mm}$ and $18 \mathrm{~mm}$ ) corresponded to about $12.5 \%$ active-area difference, which resulted in the corresponding difference (of near $12.3 \%$ ) in the measured short-circuit currents $\left(\mathrm{I}_{\mathrm{sc}}\right)$, and the maximum power output. The open-circuit voltages $\left(\mathrm{V}_{\mathrm{oc}}\right)$ were at near $17.66 \mathrm{~V}$ for all strips, and their fill factors $(\mathrm{FF})$ ranged between 0.63-0.635.

The lower-limits of the power conversion efficiency (PCE) in these custom-shaped PV strips can be evaluated using their active area, the measured electric power outputs $\left(31.68 \mathrm{~cm}^{2}\right.$ strips generated $411.2 \mathrm{~mW}$ and $35.64 \mathrm{~cm}^{2}$ strips generated $453.9 \mathrm{~mW}$ ), and a $1000 \mathrm{~W} / \mathrm{m}^{2}$ figure for the maximum total irradiation intensity. These calculations result in the average PCE (lower-limit estimate) of about $12.85 \%$, which is close to the nominal module efficiency of $13.3 \%$ specified for the original PV product (uncut Avancis circuits). Accounting for the effects of cell surface temperature, these data suggest that no noticeable efficiency reductions have occurred due to a combination of processes involving cutting the cells and substrates, making the soldered electrical connections, handling and encapsulating the custom-shaped PV modules. 


\section{Energy Harvesting Performance of Solar Concentrator Panels of Different Design Types Measured in Outdoor Experiments}

In order to evaluate the contributions of the various concentrator design features to their practical energy harvesting potential in solar window application, we characterized the electric output parameters of five samples of different structure in outdoor experiments. All concentrators had an identical energy collection (glass panel) area, but the active areas of solar cells differed slightly, as well as the glass panel structure and thicknesses. The luminescent material combinations and luminophore particle concentrations distributed inside either the epoxy- or the PVB-based lamination interlayers were identical. Inorganic luminescent materials used to down-convert the UV-blue and also some of the near-infrared light into near-IR emissions whilst partially diffusing the incident flux inside the glazing systems have been described in detail in $[10,17,28]$. The infrared-reflecting high-transparency low-emissivity coatings were also placed into principally-equivalent locations within all panel structures, at the internal (interlayer-facing) surfaces of the last glass-plate element used within each panel, in order to protect the coatings. The structure-related and component property-related technical details and data relevant to each of the samples tested are summarized in Table 1.

Table 1. Samples structure variation details.

\begin{tabular}{|c|c|}
\hline Sample ID & Glazing Structure/Solar Cells Type and Variations \\
\hline A & $\begin{array}{c}\text { Flat-glass } 200 \mathrm{~mm} \times 200 \mathrm{~mm} \text { framed window sample (Figure 2a) using low-iron glass } \\
\text { plates (one of these coated with an IR reflecting low-E film) and }(26 \pm 0.5) \text { mm-wide } \\
\text { cells (Avancis PowerMax } 3.5130, \eta_{\text {nom }}=12.2 \% \text { ) }\end{array}$ \\
\hline B & $\begin{array}{l}\text { Flat-glass } 200 \mathrm{~mm} \times 200 \mathrm{~mm} \text { concentrator sample using low-iron glass plates (one of } \\
\text { these coated with an IR reflecting low-E film) and }(16 \pm 0.5) \mathrm{mm} \text {-wide cells } \\
\left.\text { (Avancis PowerMax } 3.5140, \eta_{\text {nom }}=13.3 \%\right) .\end{array}$ \\
\hline $\mathrm{C}$ & $\begin{array}{l}\text { Sample built using three } 4 \mathrm{~mm} \text {-thick TIREX glass plates (one of these coated with an IR } \\
\text { reflecting low-E film, shown in Figure } 2 \mathrm{c}) ;(17 \pm 0.5) \mathrm{mm} \text {-wide cells } \\
\text { (Avancis PowerMax } 3.5140, \eta_{\text {nom }}=13.3 \% \text { ). }\end{array}$ \\
\hline $\mathrm{D}$ & $\begin{array}{l}\text { Sample using low-iron glass and containing four high-transparency } 100 \mathrm{~mm} \times 100 \mathrm{~mm} \\
\text { 2D (square-mesh) gratings of period } 10 \mu \mathrm{m} \text { made by lift-off lithography } \\
\text { (reported in [28]) The sample used } 2 \text { luminescent interlayers and } 4 \text { cell modules of } \\
\text { dimensions } 198 \mathrm{~mm} \times 26 \mathrm{~mm} \text { (Avancis PowerMax } 3.5130, \eta_{\text {nom }}=12.2 \% \text { ). }\end{array}$ \\
\hline E & $\begin{array}{l}\text { Sample containing four 1D diffraction gratings }(70 \mathrm{~mm} \times 130 \mathrm{~mm} \text { ) made by } \\
\text { pattern-transfer soft lithography ( period } 4 \mu \mathrm{m} \text { ) and two } 4 \mathrm{~mm} \text {-thick TIREX glass plates } \\
\text { (Figure 4). The sample used }(18 \pm 0.5) \mathrm{mm} \text {-wide PV modules (Avancis } \\
\text { PowerMax } 3.5140, \eta_{\text {nom }}=13.3 \% \text { ). }\end{array}$ \\
\hline
\end{tabular}

To evaluate the structure-related relative performance differences between the differently-constructed solar windows in the application environment for which these systems were originally intended (distributed generation of electric energy in buildings, especially for larger-area up-scaled systems, such as curtain walls), we focussed on making outdoor characterization experiments, in which the solar-cell surface temperature and real sunlight irradiation intensity are also important factors. Testing the different systems "side by side" (after stabilizing the solar-cell temperatures) provides a valuable source of data on their relative performance, even regardless of the seasonal weather-related irradiation intensity variations, if periods of stable cloud-free illumination are used. The vertically-positioned sun-facing orientation of glass panels was also selected for making the principal data and metrics comparisons, to highlight the energy-harvesting differences expected to be observed in the most typical of future practical application settings. Some measurements were also made with horizontally-placed samples, to provide another useful performance reference characterizing the ability of systems to collect solar energy from a range of flux incidence configurations. To prevent any long-term PV module (or sample) contamination, or efficiency degradation effects biasing the comparison measurements, the characterization data collected in earlier years from the older samples (A and D; the data published previously in [28]) were used throughout this article. Figure 6 summarizes 
the winter-season energy-harvesting performance differences measured in recently-constructed samples $C$ and $E$ (positioned either vertically, or horizontally, or tilted $45^{\circ}$ backwards from vertical), on two different dates (in mid-June and July 31st, 2018).
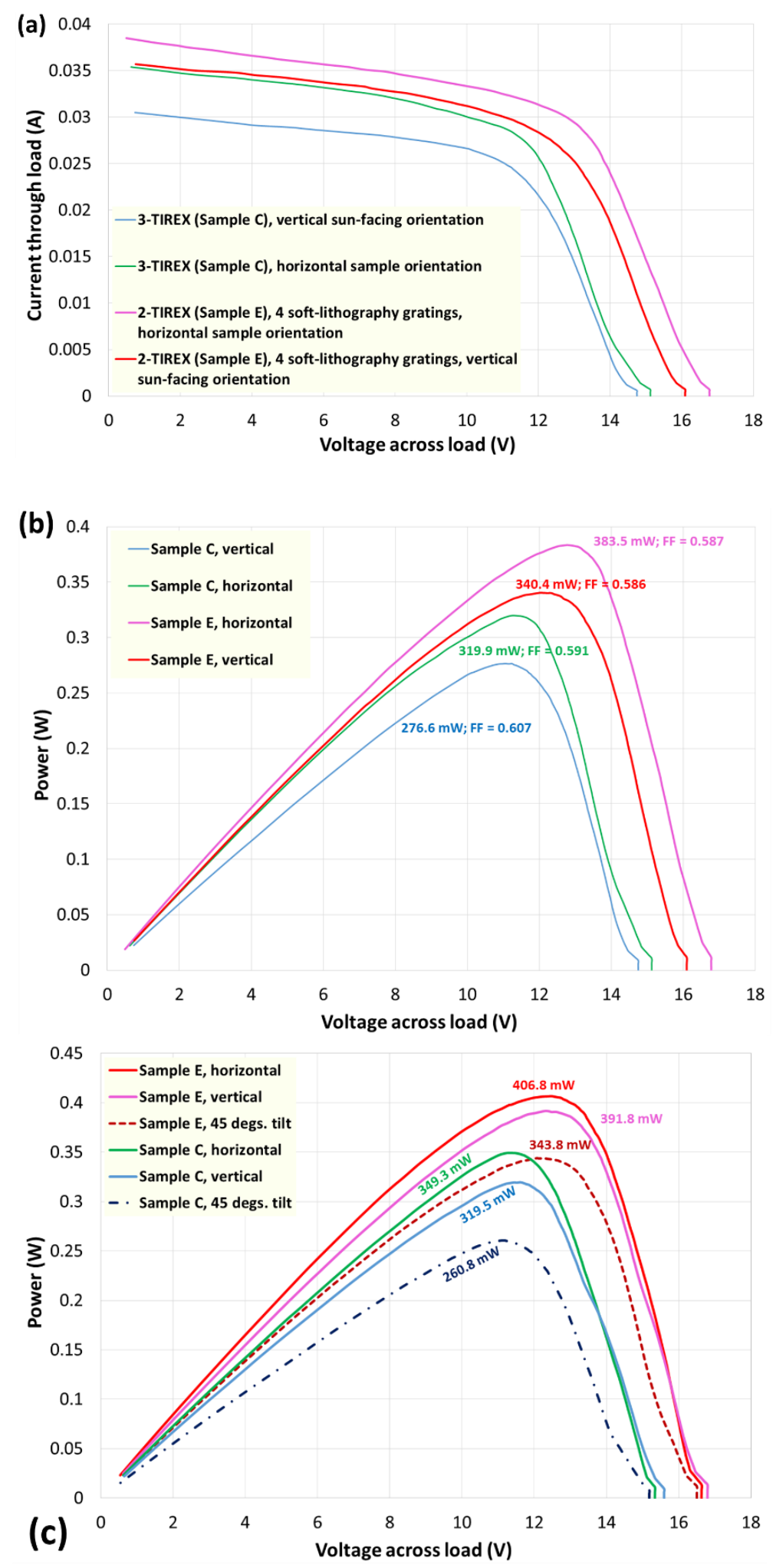

Figure 6. Cont. 


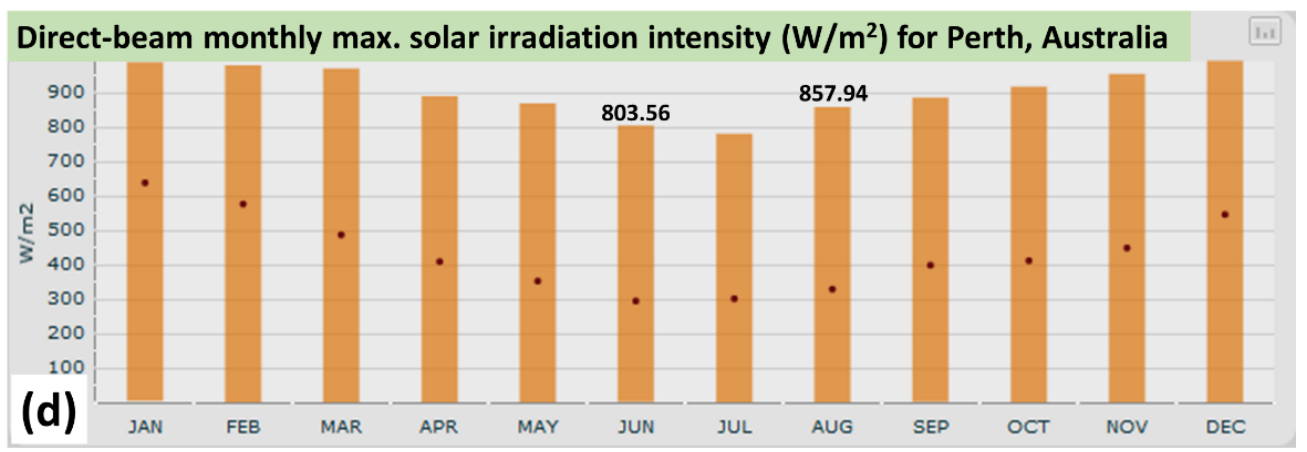

Figure 6. Solar windows performance datasets measured in winter conditions (samples C and E, measured in different orientations at midday on June 14, 2018 (a,b) and July 31, 2018 (c), in Joondalup, Western Australia). A weather conditions-related monthly irradiation intensity dataset specific to the measurement location is shown in part (d); the data were obtained using COMFEN 5 software [38].

The measurements used to generate the data of Figure 6 were performed on hazy winter days in Perth, at a low UV index and at direct-beam solar irradiation intensity not exceeding $\sim 800 \mathrm{~W} / \mathrm{m}^{2}$, with the samples placed either vertically (glass-plane normal facing towards the Sun), or horizontally onto ground during June measurements. Additional measurements made at the end of July included a $45^{\circ}$ tilted position (backwards away from vertical). According to the location-specific climate-related solar irradiation data from COMFEN 5 software, the maximum direct-beam solar irradiation intensity for June days in Perth is $803.6 \mathrm{~W} / \mathrm{m}^{2}$. Making comparative electric output measurements with solar windows in these "realistic" (non-peak) irradiation conditions is useful for making the conservative estimates of their year-round average energy-generation performance. Smaller diffused irradiation background and weaker UV flux characteristic of winter conditions are also suitable for rating the maximum power outputs of different samples with respect to one another, so that sufficiently conservative estimates of the peak-weather performance can be made, if either the instantaneous direct-beam radiation flux, or the actual measured peak-weather output of one of the samples are known. In outdoor experiments, the instantaneous solar irradiation flux is quite variable, even on clear days and during the I-V curve measurement durations of about 10s. On the other hand, multiple outdoor experiments conducted over a number of "near-peak" spring or summer days allow making reliable and repeatable measurements of the realistic "peak" power outputs at the real solar cell surface temperatures (which in our experience are typically near $40{ }^{\circ} \mathrm{C}$ in summer, thus leading to the peak outputs being underestimated by several \% compared to the standard test conditions (STC)). It is interesting to note that for samples $\mathrm{E}$ and $\mathrm{C}$, from the data of Figure $6 \mathrm{~b}$, the fractional difference between the horizontal and vertical power outputs is smaller for sample $\mathrm{E}(12.6 \%)$, compared to sample $\mathrm{C}$ $(15.6 \%)$, indicating better concentrator performance and smaller angular sensitivity of output in sample E. The data of Figure $6 \mathrm{c}$ was obtained at stronger irradiation intensity (peak monthly direct-beam irradiation dataset for August is more appropriate for analyzing the measurements made on July 31), and also confirms the smaller angular sensitivity of output in sample E. Interestingly, from the data of Figure $6 b, c$, the fractional increase in the maximum power generated by sample $C$ in the horizontal position was near $9.2 \%$, roughly corresponding to the maximum direct-beam irradiation intensity increasing by $6.85 \%$ from June to August. The power obtained from the vertically-placed samples $C$ and $\mathrm{E}$ in both cases increased by about $15 \%$, possibly due to the diffused irradiation reflected from ground surfaces reaching the sample, as well as slightly higher UV irradiation content crucial for exciting the luminophores. At peak irradiation conditions with strong UV content (e.g., in December) and when the Sun altitude angle is locally near zenith at midday, two different window positions lead typically to obtaining the maximized power output: one being near-horizontal, and another one being found at a slight tilt $\left(\sim 30^{\circ}\right)$ backwards from vertical simultaneously with added similar turn in the horizontal plane, away from the precise sun-facing position. This is because the concentrator performance relies 
both on the effects of luminescence (maximized at the highest possible excitation flux), and also the internal reflections off a IR-mirror coating [10], or diffraction, which are more effective at higher flux incidence angles. The horizontal window placement is also suitable for minimizing the electric mismatch losses caused by uneven shading of different PV modules. In winter conditions, when the UV index is very low and the Sun altitude angle is near $35^{\circ}-39^{\circ}$, weaker electric output is seen at a $45^{\circ}$ backward tilted position.

By using the previously measured near-peak power output of the vertically-positioned sun-facing sample C ( $380.6 \mathrm{~mW})$ in conjunction with the orientation-averaged measured ratio (1.21, from the data of Figure $6 \mathrm{~b}$ ) of the electric power outputs between the samples $E$ and $C$, an estimate of $460 \mathrm{~mW}$ can be made for the expected near-peak (summer conditions) output of sample $\mathrm{E}$ in the vertically-positioned sun-facing configuration. The orientation averaging of the relative electric outputs is needed for conservatism, and to reduce the possible errors due to the seasonal Sun altitude angle variations. Table 2 shows the summary of electric output data and parameters obtained during outdoor testing experiments conducted with all concentrator samples.

Table 2. Outdoor testing results obtained with sun-facing vertically-placed concentrator samples. Electric output parameters have been recorded at either the winter-time conditions, or at near-peak irradiation conditions.

\begin{tabular}{cccc}
\hline Sample ID & $\mathbf{I}_{\mathbf{s c}}(\mathbf{m A})$ & $\mathbf{V}_{\mathbf{o c}}(\mathbf{V})$ & $\mathbf{F F} / \mathbf{P}_{\mathbf{m a x}}(\mathbf{W})$ \\
\hline A & 51.5 (peak) & 15.8 & $0.489 / 0.398$ \\
B & 23 (peak) & 15.2 & $0.616 / 0.215$ \\
C & 31.5 (winter)/39.7 (peak) & $15.2 / 15.73$ & $0.609 / 0.3806$ \\
D & 73.0 (peak) & 15.5 & $0.48 / 0.543$ \\
E & 36.5 (winter)/ 44(est. peak) & $16.1 / \sim 17.0$ & $0.59 / 0.460$ (est.) \\
\hline
\end{tabular}

The PV testing datasets of different solar window samples reveal significant structure-related and design-related performance differences, highlighting in particular the contributions of diffractive elements. These data need to be analyzed more in detail, by way of comparing the energy collection performance per unit active PV cell area. Samples using older PV modules of slightly smaller efficiency (A and D) had fill factors near 0.49, whilst the newer samples (B, C, and E) had higher FF values near 0.6. The variations in $\mathrm{V}_{\mathrm{oc}}$ between the different samples were mainly due to the different spectral distributions of irradiation flux intensities reaching the active areas of cells, and also depended on cell surface temperature variations.

\section{Results and Discussion}

It is of interest to summarize the observed structure-related concentrator performance data using a standardized approach reliant on the same metrics as is used commonly in the LSC literature. Characterization of luminescent concentrator performance usually involves parameters such as geometric gain $(G$, the ratio of the total energy collection area to the solar-cells area at which the PV conversion takes place), photon collection probability at solar cell surfaces $(\mathrm{P})$, and optical concentration factor $\left(C_{\text {opt }}\right)$. These parameters are related through a simple expression $C_{o p t}=G \cdot P=G \cdot\left(\eta / \eta_{\text {nom }}\right)$, where $\eta$ is the concentrator PCE, and $\eta_{\text {nom }}$ is "bare-cell conversion efficiency" - the nominal efficiency of the solar cell module of the type used [39]. One additional metrics figure can also be proposed to characterize the electric output performance of vertically-oriented solar windows, which accounts for both the energy collection area of the glazing-system panel and the total area of PV modules installed: $\mathrm{M}=\mathrm{P}_{\max (\mathrm{vert})} /\left(\mathrm{A}_{\text {glass }} \cdot \mathrm{A}_{\mathrm{PV}}\right)$. A summary of measured concentrator performance data obtained from the batch of five differently-constructed solar window systems is shown in Table 3. Within the dataset of Table 3, all efficiency-related and $P_{\max }$ values shown relate to the parameters actually measured in outdoor illumination conditions, at the real (exposure-stabilized) solar cell temperatures. Due to the geometry of sunlight incidence onto the vertically-oriented glass panels, a factor of 0.7 is used to 
relate the system efficiency figures corresponding to the vertical and peak-tilted orientations, so that the probability of photon collection P can be calculated in a consistent way, regardless of the slight differences in the exact peak-output orientations and tilts existing between differently-constructed samples. This scaling factor is used due to the vertically-oriented glass surfaces intercepting the total solar flux of about $700 \mathrm{~W} / \mathrm{m}^{2}$ at peak weather conditions corresponding to the standardized AM1.5G spectrum and $1000 \mathrm{~W} / \mathrm{m}^{2}$ of total irradiation intensity. In all experiments conducted to obtain the metrics-related data, the solar irradiation intensity was close to the peak conditions, but at less than $1000 \mathrm{~W} / \mathrm{m}^{2}$. The expected peak output of sample E was evaluated within Section 5.

Table 3. Electric output summary and concentrator performance metrics of several $200 \mathrm{~mm} \times 200 \mathrm{~mm}$ solar windows tested in near-peak outdoor illumination conditions.

\begin{tabular}{cccccc}
\hline Sample ID & $\eta_{\text {vert }}(\%) / \eta_{\text {peak }}(\%)$ & $G$ & $\boldsymbol{P}(\%)$ & $\boldsymbol{C}_{\text {opt }}$ & $\mathbf{M}\left[\mathrm{W} /\left(\mathbf{m}^{2} \cdot \mathbf{m}^{2}{ }_{\text {cells }}\right)\right]$ \\
\hline A & $1.42 / 2.028$ & 1.94 & 16.62 & 0.322 & 483.19 \\
B & $0.743 / 1.06$ & 3.156 & 7.97 & 0.252 & 434.03 \\
C & $1.36 / 1.943$ & 2.97 & 14.61 & 0.434 & 706.70 \\
D & $1.94 / 2.77$ & 1.94 & 22.70 & 0.440 & 659.24 \\
E & $1.643 / 2.347$ & 2.806 & 17.65 & 0.495 & 806.68 (est.) \\
\hline
\end{tabular}

The results obtained show clearly the significant contributions to energy collection performance per unit active PV area provided by both specialized glass (TIREX) and diffractive elements. Interestingly, the gratings produced by soft lithography used in this study have not been optimized in terms of groove depth for high visible transparency and spectrally-selective deflection of UV and IR light, as opposed to 2D gratings used in sample D. This was due to the etching depth limitations which applied to the quartz-based master grating manufacture process. Therefore, significant room for improvement still exists, in terms of achieving the improved grating transparency simultaneously with stronger deflection of the UV and IR light, if the soft lithography gratings are further optimized in design. The trends observed in the optical concentration factor $\mathrm{C}_{\mathrm{opt}}$ also confirm the importance of concentrator design features such as specialty glass and embedded diffractive optics.

\section{Conclusions}

In summary, we have analyzed the structure-related energy-harvesting performance differences across a batch of glass-based solar windows of $400 \mathrm{~cm}^{2}$ area. Diffractive elements of 1D and also the 2D geometry type have shown significant potential for improving the light collection capability in semitransparent glass-based planar concentrator panels. In particular, employing polymer-based soft lithography pattern replication technology has been shown to be a viable strategy for the manufacture of large-area microstructured solar window panels, which more efficiently redirect a part of the incident solar energy towards the edge-mounted PV cell modules. More than $20 \%$ improvement in power conversion efficiency has been demonstrated in vertically-positioned microstructured glass concentrators, compared to flat-glass-based vertical solar windows of identical area, where both systems employed advanced high-transmission glass. Smaller angular sensitivity of the concentrator output has also been demonstrated in microstructured systems. A new performance metrics-related parameter has been introduced, which relates the electric output of solar windows to the total area of photovoltaic cells as well as the glass collector area. Improvement in this metrics parameter of up to 1.67 times has been demonstrated in a semi-transparent microstructured concentrator compared to a similar window using conventional low-iron clear glass. Glass of a special composition type designed for reduced absorption in the near infrared has been shown to provide significant concentrator performance improvements on its own, compared to using standard low-iron ultra-clear glass plates. 
Author Contributions: The Australian authors (M.V., K.A. and M.N.A.) have contributed to the design of experiments and data collection; The Korean team (M.B. and S.-M.K.) contributed by sharing their process development results and expertise in soft lithography. M.V. analyzed the data and prepared the manuscript; all authors discussed the data and the presentation; M.V. and K.A. further reviewed and improved the manuscript.

Funding: This research was funded by the Australian Research Council (grants LP130100130 and LP160101589) and Edith Cowan University.

Acknowledgments: The authors would like to acknowledge the support from ClearVue Technologies Ltd, the Australian Research Council, and Edith Cowan University.

Conflicts of Interest: The authors declare no conflict of interest.

\section{References}

1. Weber, W.H.; Lambe, J. Luminescent greenhouse collector for solar radiation. Appl. Opt. 1976, 15, $2299-2300$. [CrossRef] [PubMed]

2. Goetzberger, A.; Greube, W. Solar-energy conversion with fluorescent collectors. Appl. Phys. 1977, 14, 123-139. [CrossRef]

3. Van Sark, W.G.J.H.M.; Barnham, K.W.J.; Slooff, L.H.; Chatten, A.J.; Büchtemann, A.; Meyer, A.; McCormack, S.J.; Koole, R.; Farrell, D.J.; Bose, R.; et al. Luminescent Solar Concentrators-A review of recent results. Opt. Express 2008, 16, 21773-21792. [CrossRef] [PubMed]

4. Debije, M.G.; Verbunt, P.P.C. Thirty Years of Luminescent Solar Concentrator Research: Solar Energy for the Built Environment. Adv. Energy Mater. 2012, 2, 12-35. [CrossRef]

5. Kanellis, M.; De Jong, M.M.; Slooff, L.; Michael, G.; Debije, M.G. The solar noise barrier project: 1. Effect of incident light orientation on the performance of a large-scale luminescent solar concentrator noise barrier. Renew. Energy 2017, 103, 647-652. [CrossRef]

6. Li, H.; Wu, K.; Lim, J.; Song, H.-J.; Klimov, V.I. Doctor-blade deposition of quantum dots onto standard window glass for low-loss large-area luminescent solar concentrators. Nat. Energy 2016. [CrossRef]

7. Zhao, Y.; Lunt, R.R. Transparent luminescent solar concentrators for large-area solar windows enabled by massive stokes-shift nanocluster phosphors. Adv. Energy Mater. 2013, 3, 1143-1148. [CrossRef]

8. Meinardi, F.; Ehrenberg, S.; Dhamo, L.; Carulli, F.; Mauri, M.; Bruni, F.; Simonutti, R.; Kortshagen, U.; Brovelli, S. Highly efficient luminescent solar concentrators based on earth-abundant indirect-bandgap silicon quantum dots. Nat. Photonics 2017. [CrossRef]

9. Merkx, E.P.J.; Ten Kate, O.M.; Van Der Kolk, E. Rapid optimization of large-scale luminescent solar concentrators: Evaluation for adoption in the built environment. Opt. Express 2017, 25, A547. [CrossRef] [PubMed]

10. Alghamedi, R.; Vasiliev, M.; Nur-E-Alam, M.; Alameh, K. Spectrally-selective all-inorganic scattering luminophores for solar energy-harvesting clear glass windows. Sci. Rep. 2014, 4, 6632. [CrossRef] [PubMed]

11. Ten Kate, O.M.; Krämer, K.W.; Van der Kolk, E. Efficient luminescent solar concentrators based on self-absorption free, $\mathrm{Tm}^{2+}$ doped halides. Sol. Energy Mater. Sol. Cells 2015, 140, 115-120. [CrossRef]

12. Hughes, M.D.; Borca-Tasciuc, D.-A.; Kaminski, D.A. Highly efficient luminescent solar concentrators employing commercially available luminescent phosphors. Sol. Energy Mater. Sol. Cells 2017, 171, $293-301$. [CrossRef]

13. Traverse, C.J.; Pandey, R.; Barr, M.C.; Lunt, R.R. Emergence of highly transparent photovoltaics for distributed applications. Nat. Energy 2017, 2, 849-860. [CrossRef]

14. Bergren, M.R.; Makarov, N.S.; Ramasamy, K.; Jackson, A.; Guglielmetti, R.; McDaniel, H. High-Performance CuInS2 Quantum Dot Laminated Glass Luminescent Solar Concentrators for Windows. ACS Energy Lett. 2018, 3, 520-525. [CrossRef]

15. TIREXtreme Product Brochure, AGC Europe (2016). Available online: https://www.agc-yourglass.com/gb / en/industrial/special_compositions (accessed on 14 June 2018).

16. Martellotta, F.; Cannavale, A.; Ayr, U. Comparing energy performance of different semi-transparent, building-integrated photovoltaic cells applied to "reference" buildings. Energy Procedia 2017, 126, 219-226. [CrossRef]

17. Vasiliev, M.; Alameh, K.; Nur-E-Alam, M. Spectrally-Selective Energy-Harvesting Solar Windows for Public Infrastructure Applications. Appl. Sci. 2018, 8, 849. [CrossRef] 
18. Espeche, J.M.; Noris, F.; Lennard, Z.; Challet, S.; Machado, M. PVSITES: Building-integrated photovoltaic technologies and systems for large-scale market deployment. Proceedings 2017, 1, 690. [CrossRef]

19. Cornaro, C.; Basciano, G.; Puggioni, V.A.; Pierro, M. Energy saving assessment of semi-transparent photovoltaic modules integrated into NZEB. Buildings 2017, 7, 9. [CrossRef]

20. Khan, H.S.; Asif, M.; Mohammed, M.A. Case study of a nearly zero energy building in Italian climatic conditions. Infrastructures 2017, 2, 19. [CrossRef]

21. Rey-Hernandez, J.M.; Velasco-Gomez, E.; San Jose-Alonso, J.F.; Tejero-Gonzalez, A.; Rey-Martinez, F.J. Energy analysis at a near zero energy building. A case study in Spain. Energies 2018, 11, 857. [CrossRef]

22. Dalapati, G.K.; Kushwaha, A.K.; Sharma, M.; Suresh, V.; Shannigrahi, S.; Zhuk, S.; Masudy-Panah, S. Transparent heat regulating (THR) materials and coatings for energy saving window applications: Impact of materials design, micro-structural, and interface quality on the THR performance. Prog. Mater. Sci. 2018, 95, 45-131. [CrossRef]

23. El Mouedden, Y.; Alghamedi, R.; Nur-E-Alam, M.; Vasiliev, M.; Alameh, K. Thin film coatings for solar and thermal radiation control prepared by physical vapour deposition. In Proceedings of the 9th International Conference on High Capacity Optical Networks and Enabling Technologies (HONET), Istanbul, Turkey, 12-14 December 2012.

24. Rezaei, S.D.; Shannigrahi, S.; Ramakrishna, S. A review of conventional, advanced, and smart glazing technologies and materials for improving indoor environment. Sol. Energy Mater. Sol. Cells 2017, 159, $26-51$. [CrossRef]

25. Lu, C.; Raghunathan, V.; Roy, K. Efficient Design of Micro-Scale Energy Harvesting Systems. IEEE J. Emerg. Sel. Top. Circuits Syst. 2011, 1, 254-266. [CrossRef]

26. Li, D.; Chou, P. Maximizing efficiency of solar-powered systems by load matching. In Proceedings of the International Symposium on Low Power Electronics and Design, Newport Beach, CA, USA, 11 August 2004; pp. 162-167.

27. Chou, P.; Kim, S. Techniques for maximizing efficiency of solar energy harvesting systems. In Proceedings of the 5th Conference on Mobile Computing and Ubiquitous Networking, Seattle, WA, USA, 26-28 April 2010.

28. Vasiliev, M.; Alghamedi, R.; Nur-E-Alam, M.; Alameh, K. Photonic microstructures for energy-generating clear glass and net-zero energy buildings. Sci. Rep. 2016, 6, 31831. [CrossRef] [PubMed]

29. Rosenberg, V.; Vasiliev, M.; Alameh, K. A Spectrally Selective Luminescence Concentrator Panel with a Photovoltaic cell. Patent EP 2726920 B1, 2017.

30. De Jong, T.M.; De Boer, D.K.G.; Bastiaansen, C.W.M. Diffractive flat panel solar concentrators of a novel design. Opt. Express 2016, 24, A1138. [CrossRef] [PubMed]

31. Cocilovo, B.; Hashimura, A.; Tweet, D.J.; Voutsas, T.; Norwood, R.A. Highly transparent light-harvesting window film. Appl. Opt. 2015, 54, 8990-8998. [CrossRef] [PubMed]

32. Xia, Y.; Whitesides, G.M. Soft Lithography. Ann. Rev. Mater. Sci. 1998, 28, 153-184. [CrossRef]

33. Lee, T.W.; Mitrofanov, O.; Hsu, J. Pattern-Transfer Fidelity in Soft Lithography: The Role of Pattern Density and Aspect Ratio. Adv. Funct. Mater. 2005, 15, 1683-1688. [CrossRef]

34. Guo, L.J. Nanoimprint Lithography: Methods and Material Requirements. Adv. Mater. 2007, 19, 495-513. [CrossRef]

35. Badshah, M.A.; Jang, H.; Kim, Y.K.; Kim, T.-H.; Kim, S.-M. Development of a rapid cure polydimethylsiloxane replication process with near-zero shrinkage. J. Micro/Nanolith. Mems Moems 2014, 13, 033006. [CrossRef]

36. Badshah, M.A.; Kim, J.; Jang, H.; Kim, S.M. Fabrication of Highly Packed Plasmonic Nanolens Array Using Polymer Nanoimprinted Nanodots for an Enhanced Fluorescence Substrate. Polymers 2018, 10, 649. [CrossRef]

37. Han, Y.-A.; Byeon, E.; Kim, J.; Kim, S.-M. A Simulation Model Considering Sidewall Deposition for the Precise Prediction of the Performance of Label-Free Photonic-Crystal Biosensors. J. Nanosci. Nanotechnol. 2012, 12, 5429-5434. [CrossRef] [PubMed] 
38. COMFEN5 software, Berkeley Lab, USA. Available online: https://windows.lbl.gov/tools/comfen/ software-download (accessed on 15 July 2018).

39. Desmet, L.; Ras, A.J.M.; de Boer, D.K.G.; Debije, M.G. Monocrystalline silicon photovoltaic luminescent solar concentrator with $4.2 \%$ power conversion efficiency. Opt. Lett. 2012, 37, 3087-3089. [CrossRef] [PubMed]

(C) 2018 by the authors. Licensee MDPI, Basel, Switzerland. This article is an open access article distributed under the terms and conditions of the Creative Commons Attribution (CC BY) license (http://creativecommons.org/licenses/by/4.0/). 